\title{
Meropenem Prevents Levofloxacin-Induced Resistance in Penicillin-Resistant Pneumococci and Acts Synergistically with Levofloxacin in Experimental Meningitis
}

Published online: 14 October 2003

(C) Springer-Verlag 2003

\begin{abstract}
The aim of the present study was to investigate the potential synergy between meropenem and levofloxacin in vitro and in experimental meningitis and to determine the effect of meropenem on levofloxacininduced resistance in vitro. Meropenem increased the efficacy of levofloxacin against the penicillin-resistant pneumococcal strain KR4 in time-killing assays in vitro and acted synergistically against a second penicillinresistant strain WB4. In the checkerboard, only an additive effect (FIC indices: 1.0) was observed for both strains. In cycling experiments in vitro, levofloxacin alone led to a 64-fold increase in the MIC for both strains after 12 cycles. Addition of meropenem in sub-MIC concentrations $(0.25 \times \mathrm{MIC})$ completely inhibited the selection of levofloxacin-resistant mutants in WB4 after 12 cycles. In $\mathrm{KR} 4$, the addition of meropenem led to just a twofold increase in the MIC for levofloxacin after 12 cycles. Mutations detected in the genes encoding for topoisomerase IV (parC) and gyrase ( gyrA) confirmed the levofloxacin-induced resistance in both strains. Addition of meropenem was able to completely suppress levofloxacin-induced mutations in WB4 and led to only one mutation in parE in KR4. In experimental meningitis, meropenem, given in two doses $(2 \times 125 \mathrm{mg} / \mathrm{kg})$, produced a good bactericidal activity $\left(-0.45 \Delta \log _{10} \quad \mathrm{cfu} / \mathrm{ml} \cdot \mathrm{h}\right)$ comparable to one dose $(1 \times 10 \mathrm{mg} / \mathrm{kg})$ of levofloxacin $\left(-0.44 \Delta \log _{10} \mathrm{cfu} / \mathrm{ml} \cdot \mathrm{h}\right)$ against the penicillin-resistant
\end{abstract}

P. Cottagnoud $(\bullet) \cdot$ A. Stucki

Department of Internal Medicine,

Inselspital, Freiburgstrasse, 3010 Bern, Switzerland

e-mail: pcottagn@insel.ch

Tel.: +41-31-6323472

Fax: +41-31-6323847

M. Cottagnoud · F. Acosta - L. Flatz · F. Kühn

Department of Internal Medicine,

Spital Bern-Ziegler,

Bern, Switzerland

J. Entenza

Department of Infectious Diseases,

CHUV, Lausanne, Switzerland strain WB4. Meropenem combined with levofloxacin acted synergistically $\left(-0.93 \Delta \log _{10} \mathrm{cfu} / \mathrm{ml} \cdot \mathrm{h}\right)$, sterilizing the CSF of all rabbits.

\section{Introduction}

For clinicians and infectiologists, the worldwide increase in penicillin-resistant pneumococci remains a matter of major concern. In the USA, the resistance rates increased rapidly over the past years, reaching 33\% in 1999 [1]. In some cases, additional resistance to cephalosporins has further reduced the therapeutic options for infections with penicillin-resistant strains. Besides increasing isolation of quinolone-resistant strains in several countries [2, 3, 4], more alarming is the report of treatment failure with quinolones due to the emergence of resistance during treatment [5]. Until now, $\beta$-lactam antibiotics have remained the drugs of choice for pneumococcal infections, except when their penetration into infected tissues is limited, as is the case in meningitis. Based on actual recommendations, a combination of a cephalosporin with vancomycin is recommended for meningitis due to resistant strains [6]. However, the efficacy of this antibiotic regimen might be jeopardized, since vancomycin- and cephalosporin-tolerant pneumococci associated with treatment failures have been isolated recently [7]. A potent antibiotic regimen that does not lead to emergence of resistance would represent a major progress. Meropenem is a carbapenem with a broad antibacterial spectrum and a good activity against penicillin-resistant pneumococci in experimental meningitis [8].

In this study we have investigated the potential synergy between meropenem and levofloxacin in vitro and in experimental meningitis and the effect of meropenem on levofloxacin-induced resistance in vitro. 


\section{Materials and Methods}

Study Strains and Determination

of Minimal Inhibitory Concentrations

The two pneumococcal strains (WB4 and KR4) were originally isolated from two patients with pneumonia at the University Hospital of Bern, Switzerland. The MICs for WB4 were as follows: penicillin $4 \mathrm{mg} / \mathrm{l}$, ceftriaxone $0.5 \mathrm{mg} / \mathrm{l}$, meropenem $0.5 \mathrm{mg} / \mathrm{l}$, vancomycin $0.12-0.25 \mathrm{mg} / \mathrm{l}$, levofloxacin $1 \mathrm{mg} / \mathrm{l}$, gatifloxacin $0.12-$ $0.25 \mathrm{mg} / \mathrm{l}$, moxifloxacin $0.12 \mathrm{mg} / \mathrm{l}$, and garenoxacin $0.03 \mathrm{mg} / \mathrm{l}$. The MICs of KR4 were as follows: penicillin $4 \mathrm{mg} / \mathrm{l}$, ceftriaxone $0.5 \mathrm{mg} / \mathrm{l}$, meropenem $0.5 \mathrm{mg} / \mathrm{l}$, vancomycin $0.12-0.25 \mathrm{mg} / \mathrm{l}$, levofloxacin $1 \mathrm{mg} / \mathrm{l}$, gatifloxacin $0.25 \mathrm{mg} / \mathrm{l}$, moxifloxacin $0.12 \mathrm{mg} / \mathrm{l}$, and garenoxacin $0.015 \mathrm{mg} / \mathrm{l}$.

MICs were determined by the macrodilution broth method. The MIC was defined as the lowest concentration that inhibited visible growth after 12 and $24 \mathrm{~h}$ of incubation at $37^{\circ} \mathrm{C}$.

\section{Rabbit Meningitis Model}

The meningitis model, originally described by Dacey and Sande [9] was used in this study. The experimental protocol was accepted by the local ethical committee (Veterinäramt des Kantons Bern). Young New Zealand White rabbits weighing $2-2.5 \mathrm{~kg}$ were anesthetized by intramuscular injections of ketamine $(30 \mathrm{mg} / \mathrm{kg}$ ) and xylazine $(15 \mathrm{mg} / \mathrm{kg})$ and were immobilized in stereotactic frames for induction of meningitis and sampling of colony-forming units (cfu). An inoculum containing approximately $10^{5} \mathrm{cfu}$ of penicillin-resistant strain WB4 was instilled in the cisterna magna. A long-acting anesthetic drug (ethylcarbamate [urethane]: $3.5 \mathrm{~g}$ / rabbit) was injected subcutaneously, and animals were returned to their cages. Fourteen hours later a catheter was introduced into the femoral artery for serum sampling, and the cisterna magna was punctured again for periodic CSF sampling before and 1, 2, 4, 5, 6, and $8 \mathrm{~h}$ after initiation of therapy. Anesthesia was performed by repetitive injections of pentobarbital sodium. Blood samples for measuring meropenem and levofloxacin concentrations were drawn at $0.25,0.5,1,1.5,2,3,4,4.25,4.5,5,6$, and $8 \mathrm{~h}$ after antibiotic administration. Antibiotics were administered by a peripheral ear vein at the following concentrations: meropenem $125 \mathrm{mg} / \mathrm{kg}$ and levofloxacin $10 \mathrm{mg} / \mathrm{kg}$ of body weight. Meropenem was injected at hours 0 and 4 and levofloxacin only at hour 0 . All antibiotics and anesthetic drugs were purchased commercially.

Bacterial titers were measured by 10 -fold serial dilutions of CSF samples, plated on blood agar plates containing 5\% sheep blood, and incubated overnight at $37^{\circ} \mathrm{C}$. In parallel, $20 \mu \mathrm{l}$ of undiluted samples were plated (limit of detectability: $50 \mathrm{cfu} / \mathrm{ml}$ ). Comparison between dilutions of CSF was used to exclude significant carryover effects during therapy. The antimicrobial activity of the different regimens during the 8-h treatment was calculated by linear regression analysis and expressed as change in $\log _{10}$ cfu per milliliter per hour and as change of viable count over $8 \mathrm{~h}$. A value of 1.7 ( $\log _{10}$ of the limit of detectability) was assigned to the first sterile CSF sample, and a value of 0 was assigned to any following sterile CSF sample. The results are expressed as means \pm standard deviation. Statistical significance was determined by the Newman-Keuls test.

\section{Determination of Antibiotic Levels in Cerebrospinal Fluid}

Antibiotic concentrations in the CSF were measured by the agar diffusion method. Standard curves were performed in saline with $5 \%$ rabbit serum in order to mimic CSF protein concentration [10]. Bacillus subtilis ATCC 6633 was used as test strain for levofloxacin and meropenem [11]. The inter- and intraday variability was approximately $10 \%$. The limits of detection were $0.3 \mathrm{mg} / \mathrm{l}$ for meropenem and for levofloxacin.
In Vitro Killing Assays

The two pneumococcal strains (WB4 and KR4) were grown in $\mathrm{C}+\mathrm{Y}$ medium [12] to an optical density of 0.3 at $590 \mathrm{~nm}$ and then diluted 40-fold to $10^{6} \mathrm{cfu}$, corresponding approximately to the CSF bacterial titer in rabbits before initiation of therapy. Meropenem was added in sub-MIC concentrations $(0.5 \times$ MIC against KR 4 and WB4) and levofloxacin in concentrations corresponding to the MIC. Bacterial titers were determined at $0,2,4,6$, and $8 \mathrm{~h}$ by serial dilution of samples, plated on agar plates containing 5\% sheep blood, and incubated at $37^{\circ} \mathrm{C}$ for $24 \mathrm{~h}$. Experiments were performed in triplicate, and results are expressed as means \pm standard deviation. Synergy was defined as the bactericidal activity of a combination regimen significantly superior to the sum of each substance.

Determination of Fractional Inhibitory Concentration Index

Fractional inhibitory concentration (FIC) indices were measured using the checkerboard method as described previously [13]. In brief, the two pneumococcal strains (WB4 and KR4) were grown in $\mathrm{C}+\mathrm{Y}$ medium until the logarithmic growth phase (optical density 0.3 at $590 \mathrm{~nm}$ ) and were then diluted 1:40. Approximately 0.5$1 \times 10^{6} \mathrm{cfu}$ were pipetted into microtiter trays containing concentrations of levofloxacin and meropenem that ranged from $0.03125 \times \mathrm{MIC}$ to $2 \times \mathrm{MIC}$. Microtiter plates were incubated at $37^{\circ} \mathrm{C}$ for $24 \mathrm{~h}$. After 6,12 , and $24 \mathrm{~h}$, the plates were read for detection of inhibition of bacterial growth. The experiments were performed in duplicate and were repeated once. FIC indices were calculated by the method of Eliopoulos and Moellering [14]. Synergy was defined as an FIC index of $\leq 0.5$, additivity was defined as an FIC index of $>0.5-\leq 4$, and antagonism was defined as an FIC index of $>4$.

\section{Selection of Quinolone-Resistant Derivatives in Vitro}

Experiments were designed to test the tendency of levofloxacin to select resistant strains in liquid cultures. Large inocula $\left(10^{7}\right.$ $10^{8} \mathrm{cfu} / \mathrm{ml}$ ) of either WB4 or KR4 were exposed to stepwise increasing concentrations of antibiotics [15]. Series of tubes containing twofold increasing concentrations of levofloxacin were incubated either with WB4 or KR4 $\left(10^{7}-10^{8} \mathrm{cfu} / \mathrm{ml}\right)$, as for MIC determination. After $12 \mathrm{~h}$ of incubation, $0.1-\mathrm{ml}$ samples from the tubes containing the highest antibiotic concentration and still showing turbidity were used to inoculate a new series of tubes containing serial dilutions of antibiotic. The experiments were performed during 12 cycles. The MIC was determined after each cycle.

In parallel, the same experimental protocol was used, but meropenem was added in low concentrations $(0.12 \mathrm{mg} / \mathrm{l}$, corresponding to $0.25 \times \mathrm{MIC}$ for the 2 strains) to the tubes containing serial dilutions of levofloxacin. After $12 \mathrm{~h}$ of incubation, the MIC was determined as described above in tubes containing only levofloxacin.

Preparation of Chromosomal DNA, PCR Amplification, and DNA Sequence Analysis

Chromosomal pneumococcal DNA was prepared as described [16]. PCR-amplification of the parC, parE, gyrA, and $g y r B$ genes was performed according to a published method [17]. PCR amplification was performed with a GeneAmp PCR system 9,700 apparatus (Perkin Elmer, USA). After amplification, PCR products were purified by using a QIAquick PCR purification kit (Quiagen, Switzerland). Nucleotide sequencing for the PCR amplicons was carried out by using the ABI PRISM Dye Terminator Cycle Sequencing Ready Reaction kit according to the protocol of the manufacturer (Perkin Elmer). An ABI PRISM 377 DNA sequencer was used for sequencing. All testing was performed in duplicate. 


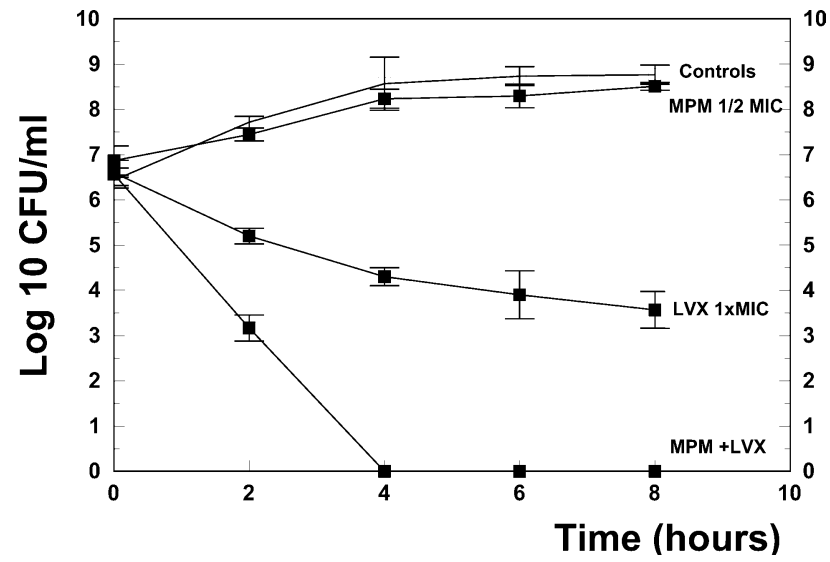

Fig. 1 Killing rates of meropenem (MPM $0.5 \times$ MIC), levofloxacin (LVX 1×MIC), and meropenem combined with levofloxacin $(\mathrm{MPM}+\mathrm{LVX})$ for the penicillin-resistant strain WB4. Experiments were performed in triplicate, and killing rates were expressed as means \pm standard deviation

\section{Results}

In time-killing assays, the antibiotics were used at concentrations producing only negligible antibacterial activity when used as monotherapies (meropenem: $0.5 \times$ MIC, levofloxacin $1 \times \mathrm{MIC}$ ) in order to detect potential synergy between the antibiotics. Against WB4, $0.5 \times$ MIC of meropenem did not produce any bactericidal activity, with bacterial titers comparable to the untreated controls after $8 \mathrm{~h}$ (Fig. 1). Levofloxacin (1×MIC) led to a decrease in the viable cell counts of around $3 \log _{10} \mathrm{cfu} / \mathrm{ml}$ over $8 \mathrm{~h}$. The combination regimen acted synergistic and managed to sterilize the cultures already after $4 \mathrm{~h}$. Against $\mathrm{KR} 4,0.5 \times \mathrm{MIC}$ of meropenem produced a negligible decrease in the bacterial titer $\left(-0.7 \log _{10} \mathrm{cfu} / \mathrm{ml}\right.$ over $\left.8 \mathrm{~h}\right)$. Levofloxacin monotherapy $(1 \times \mathrm{MIC})$ produced an antibacterial effect of $3 \log _{10} \mathrm{cfu} / \mathrm{ml}$ over $8 \mathrm{~h}$. Due to the mean variation of the test system, the combination treatment was only additive (Fig. 2). Synergy was defined as bactericidal effect of a drug combination significantly exceeding the sum of the bactericidal effects of each agent alone [18]. In the checkerboard, the effect of the combination was only additive, with FIC indices of 1 for both strains.

On the basis of on a previously described protocol [19], levofloxacin-resistant mutants were selected by sequential incubation of both pneumococcal strains with different levofloxacin concentrations during 12 cycles. In WB4, the MIC of levofloxacin increased to $8 \mathrm{mg} / \mathrm{l}$ already after two cycles and reached $64 \mathrm{mg} / \mathrm{l}$ after six cycles, remaining stable during the last cycles. The addition of meropenem in sub-MIC concentration $(0.25 \times \mathrm{MIC})$ completely impeded levofloxacin-induced resistance over 12 cycles (Fig. 3). The stepwise increase in the MIC by sequential incubation with levofloxacin correlated with mutations detected in the two target genes that led to amino acid changes in the subunits of the enzymes $($ Ser79 $\rightarrow$ Tyr in ParC and Glu85 $\rightarrow$ Lys in GyrA; Table 1$)$.

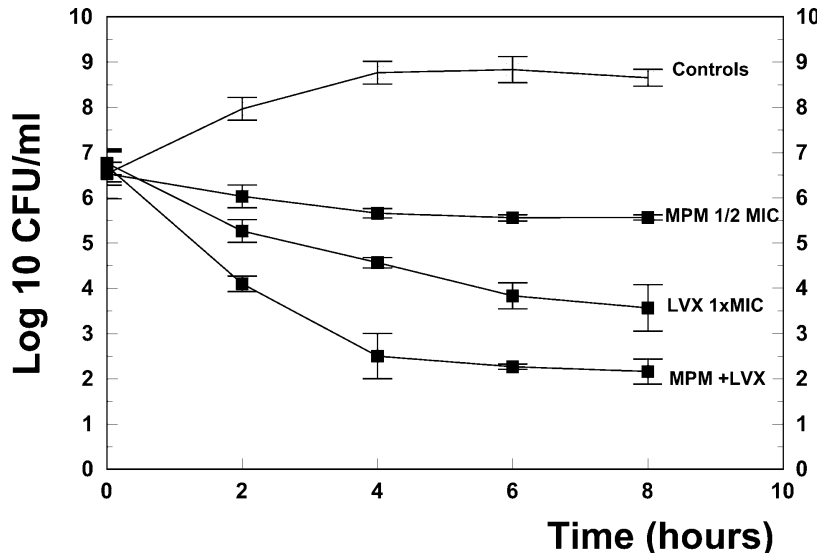

Fig. 2 Killing rates of meropenem (MPM $0.5 \times$ MIC), levofloxacin (LVX 1×MIC), and meropenem combined with levofloxacin $(\mathrm{MPM}+\mathrm{LVX})$ for the penicillin-resistant strain KR4. Experiments were performed in triplicate, and killing rates were expressed as means \pm standard deviation

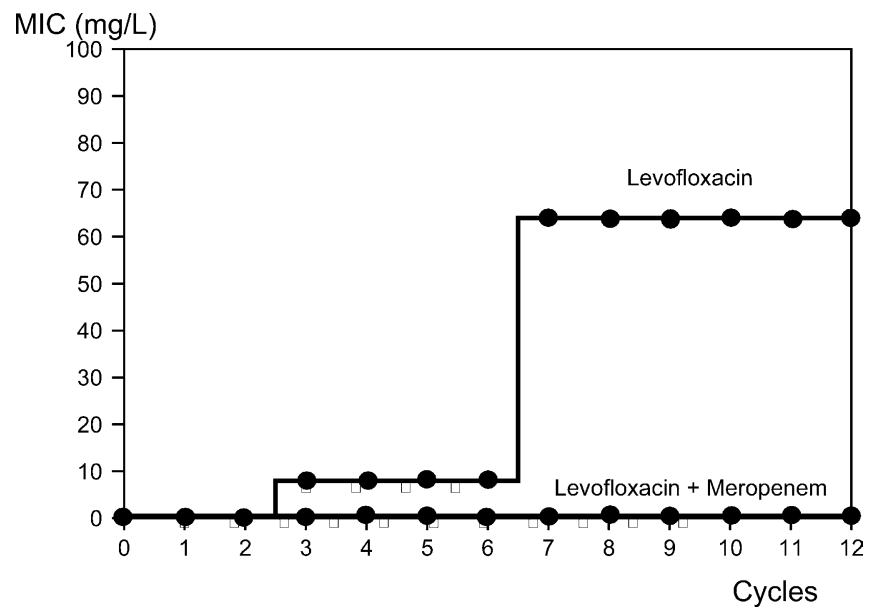

Fig. 3 Selection of levofloxacin-resistant mutants of Streptococcus pneumoniae WB4 exposed to stepwise increasing concentrations of levofloxacin alone or in combination with a sub-MIC concentration $(0.25 \times \mathrm{MIC})$ of meropenem

With the combination regimen, no mutation was detected. With the second strain (KR4), the development of levofloxacin-induced resistance occurred in a similar way. The MIC of levofloxacin increased eightfold after two cycles and 64-four-fold after eight cycles, remaining stable until the end of the experimental period (Fig. 4). The addition of meropenem led to a twofold increase in the MIC of levofloxacin for KR4, occurring after nine cycles. Levofloxacin monotherapy induced two mutations in $\operatorname{parC}(\mathrm{Ser} 79 \rightarrow$ Tyr and Asp83 $\rightarrow$ Tyr) and one mutation in gyrA (Glu85 $\rightarrow$ Lys). With the combination regimen, only one mutation was detected in parE (Asp435 $\rightarrow$ Asn). It is interesting to note that the addition of meropenem in low concentrations $(0.25 \times \mathrm{MIC})$ did not influence the MIC of levofloxacin. No cross-resistance between meropenem and levofloxacin was observed. Sequential incubation of 
Table 1 Mutations in topoisomerase IV (ParC and ParE) and gyrase (GyrA and GyrB) before and after cyclic exposure to levofloxacin (LVX) alone or in combination with meropenem (MPM) in two penicillin-resistant pneumococcal strains (WB4 and KR4)

\begin{tabular}{|c|c|c|c|c|}
\hline Strain & ParC & ParE & GyrA & GyrB \\
\hline WB4 & none & none & none & none \\
\hline WB4 + LVX & 79Ser $\rightarrow$ Phe & none & $85 \mathrm{Glu} \rightarrow$ Lys & none \\
\hline WB4 + (LVX + MPM $)$ & none & none & none & none \\
\hline KR4 & none & none & none & none \\
\hline KR4 + LVX & $\begin{array}{l}\text { 79Ser } \rightarrow \text { Phe } \\
\text { 83Asp } \rightarrow \text { Tyr }\end{array}$ & none & 85Glu $\rightarrow$ Lys & none \\
\hline $\mathrm{KR} 4+(\mathrm{LVX}+\mathrm{MPM})$ & none & 435Asp $\rightarrow$ Asn & none & none \\
\hline
\end{tabular}

Table 2 MICs of levofloxacin (LVX) alone and in combination with subinhibitory concentrations of meropenem (MPM) for two penicillin-resistant strains (WB4 and KR4)

\begin{tabular}{lllllll}
\hline & \multicolumn{2}{l}{ MIC $(\mathrm{mg} / \mathrm{l})$} & & & \\
\cline { 2 - 7 } & WB4 & WB4 LVX & WB4 LVX + MPM & KR4 & KR4 LVX & KR4 LVX + MPM \\
\hline Levofloxacin & 1 & 64 & 1 & 1 & 64 & 2 \\
Meropenem & 0.5 & 0.5 & 0.5 & 0.5 & 0.5 & 0.5 \\
\hline
\end{tabular}

WB4, quinolone-susceptible but penicillin-resistant parent pneumococcus (MIC, $4 \mathrm{mg} / \mathrm{l}$ ); WB4 LVX, levofloxacin-resistant derivative selected by passages on this drug, KR4, quinolone-susceptible but penicillin-resistant parent pneumococcus (MIC, 4 mg/l); KR4 LVX, levofloxacin-resistant derivative selected by passages on this drug; WB4 LVX + MPM or KR4 LVX + MPM, same as above, cycled in the presence of subinhibitory concentrations of meropenem

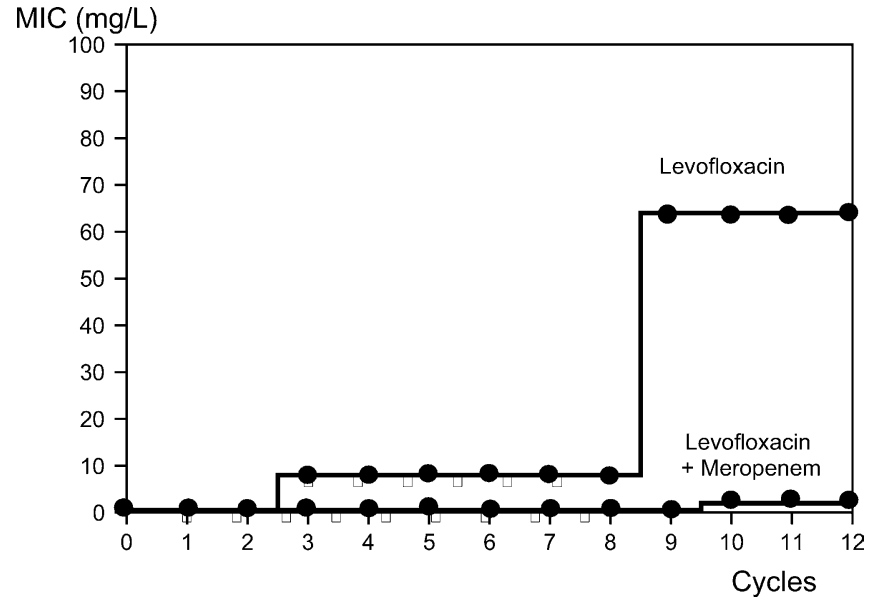

Fig. 4 Selection of levofloxacin resistant mutants of Streptococcus pneumoniae KR4 exposed to stepwise increasing concentrations of levofloxacin alone or in combination with a sub-MIC concentration $(0.25 \times \mathrm{MIC})$ of meropenem

the two pneumococcal strains with levofloxacin did not change the MIC of meropenem (Table 2).

The kinetics of the antibiotics is described in Fig. 5 and Fig. 6. Fifteen minutes after the first dose $(125 \mathrm{mg} / \mathrm{kg})$ of meropenem, serum levels peaked at $70 \mathrm{mg} / \mathrm{l}$ and decreased slowly to $1.5 \mathrm{mg} / \mathrm{l} 4 \mathrm{~h}$ later. The second injection led to peak levels around $110 \mathrm{mg} / \mathrm{l}$, declining to $2.0 \mathrm{mg} / \mathrm{l}$ after the end of the treatment period (data not shown). In the CSF, meropenem levels ranged between 4.7 and $1.3 \mathrm{mg} / \mathrm{l}$ and between 5.4 and $1.25 \mathrm{mg} / \mathrm{l}$ after the second injection (Fig. 5). During the entire treatment period, meropenem CSF levels remained above the MIC $(0.5 \mathrm{mg} / \mathrm{l}$ for WB4).

One injection of levofloxacin $(10 \mathrm{mg} / \mathrm{kg})$ led to serum peak levels around $19 \mathrm{mg} / \mathrm{l}$ after $15 \mathrm{~min}$, decreasing

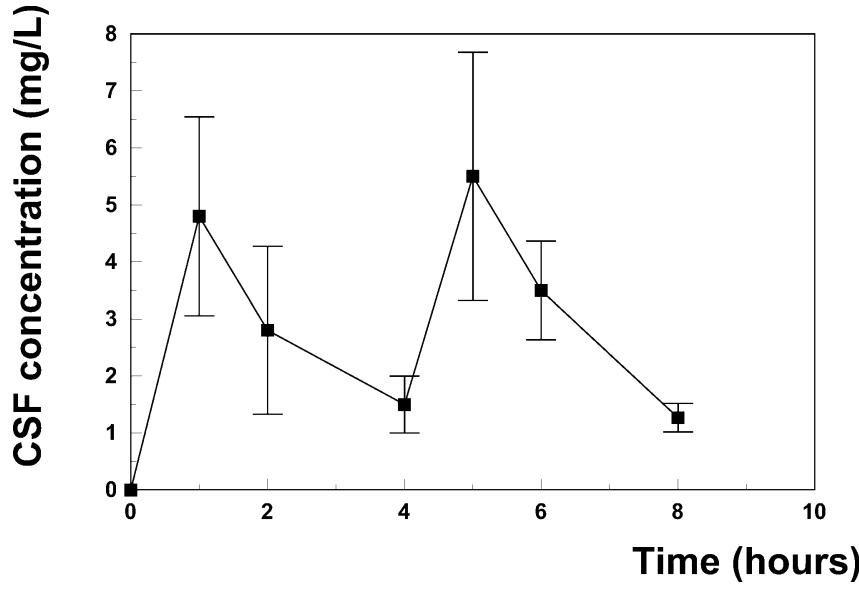

Fig. 5 Meropenem CSF concentrations after two injections of meropenem $(125 \mathrm{mg} / \mathrm{kg})$. The concentration of meropenem remained above the MIC $(0.5 \mathrm{mg} / \mathrm{l})$ throughout the treatment period

slowly to $9 \mathrm{mg} / \mathrm{l}$ after $2 \mathrm{~h}$, to $6.1 \mathrm{mg} / \mathrm{l}$ after $4 \mathrm{~h}$, and to $4 \mathrm{mg} / \mathrm{l}$ after $6 \mathrm{~h}$. At the end of the treatment, the serum levels ranged around $1.2 \mathrm{mg} / \mathrm{l}$ (data not shown). In the $\mathrm{CSF}$, the peak levels reached $3.4 \mathrm{mg} / \mathrm{l}$, decreasing continuously to $1.05 \mathrm{mg} / \mathrm{l}$ at the end of the experiment (Fig. 6). The levofloxacin CSF levels remained above the MIC $(0.5 \mathrm{mg} / \mathrm{l})$ during the entire treatment period.

The antibacterial activity of the different regimens in the experimental meningitis model is presented in Table 3. In untreated controls, bacterial titers remained more or less stable, increasing only marginally during $8 \mathrm{~h}$ $\left(+0.28 \pm 0.11 \quad \log _{10} \quad \mathrm{cfu} / \mathrm{ml}\right)$. Meropenem monotherapy produced a good antibacterial activity $(-0.45 \pm 0.12$ $\Delta \log _{10} \mathrm{cfu} / \mathrm{ml} . \mathrm{h}$ ), sterilizing the CSF of two of eight rabbits at the end of the treatment period. Levofloxacin monotherapy produced similar killing rates $(-0.44 \pm 0.13$ 
Table 3 Single drug and combination therapy against penicillin-resistant Streptococcus pneumoniae WB4 in experimental meningitis

\begin{tabular}{lllll}
\hline Antibiotic & No. of rabbits & \multicolumn{3}{l}{ Mean value \pm SD } \\
\cline { 2 - 5 } & & Initial titer $\left(\log _{10} \mathrm{cfu} / \mathrm{ml}\right)$ & Killing rate $\left(\Delta \log _{10} \mathrm{cfu} / \mathrm{ml} \cdot \mathrm{h}\right)$ & $\mathrm{Killing} \mathrm{rate} / 8 \mathrm{~h}\left(\log _{10} \mathrm{cfu} / \mathrm{ml}\right)$ \\
\hline Controls & 5 & $6.05 \pm 0.50$ & $+0.09 \pm 0.35^{\mathrm{a}}$ & $+0.28 \pm 0.11^{\mathrm{a}}$ \\
Meropenem & 8 & $5.85 \pm 0.45$ & $-0.45 \pm 0.12^{\mathrm{b}}$ & $-3.80 \pm 0.90^{\mathrm{b}}$ \\
Levofloxacin & 8 & $6.11 \pm 0.93$ & $-0.44 \pm 0.13^{\mathrm{b}}$ & $-3.40 \pm 0.66^{\mathrm{b}}$ \\
Levofloxacin + & 8 & $6.18 \pm 0.53$ & $-0.93 \pm 0.14^{\mathrm{b}}$ & $-6.18 \pm 0.53^{\mathrm{b}}$ \\
meropenem & & & &
\end{tabular}

${ }^{a} P<0.05$ versus all groups

b $P<0.05$, levofloxacin + meropenem versus all monotherapies

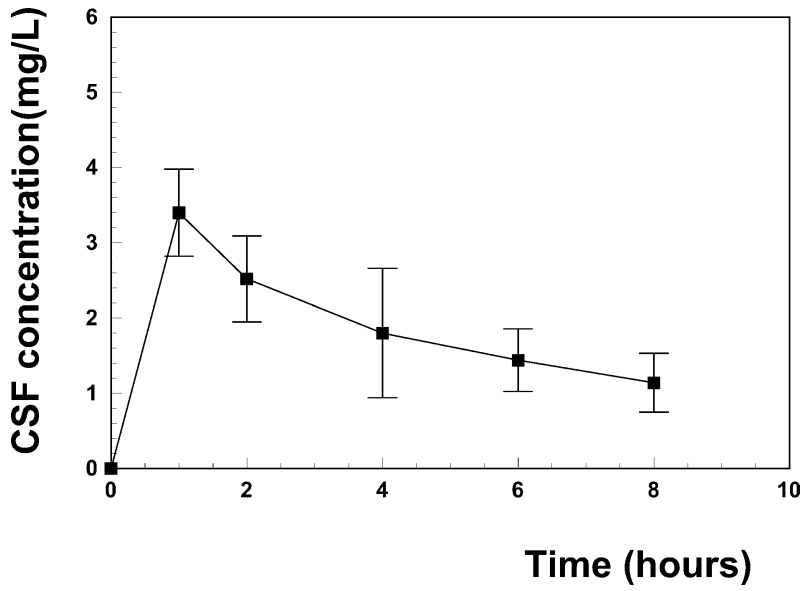

Fig. 6 Levofloxacin CSF concentrations after one injection of levofloxacin $(10 \mathrm{mg} / \mathrm{kg})$. The concentration of levofloxacin remained above the MIC $(1 \mathrm{mg} / \mathrm{l})$ throughout the treatment period

$\left.\Delta \log _{10} \mathrm{cfu} / \mathrm{ml} . \mathrm{h}\right)$ and sterilized the CSF of one of eight rabbits. The combination treatment (levofloxacin combined with meropenem) was highly efficacious $\left(-0.93 \pm 0.14 \Delta \log _{10} \mathrm{cfu} / \mathrm{ml} / \mathrm{h}\right)$ and sterilized the CSF in all rabbits. The CSF of six of eight rabbits was already sterile after $6 \mathrm{~h}$.

\section{Discussion}

Over the last decades, pneumococci have managed to resist the action of antibiotics by developing several mechanisms. They modified target structures, i.e. penicillin-binding proteins (PBPs) to elude the effect of $\beta$ lactam agents. To avoid the effect of quinolones, they altered gyrase and topoisomerase IV or activated efflux pumps, jeopardizing the efficacy of this class of antibiotics. Recently published reports about the emergence of vancomycin- and cephalosporin-tolerant strains leading to treatment failures in cases of pneumococcal meningitis are a matter of major concern [7]. Even more alarming is the emergence of quinolone resistance during therapy, which limits the use of these antibiotics as monotherapy. The aim of this study was to test a highly bactericidal regimen for pneumococcal meningitis that might, in some circumstances, reduce the risk of development of quinolone-induced resistance.

In vitro, an increased efficacy of the combination was found in time-killing assays, although the combination showed no synergism in the checkerboard with FIC indices of 1.0. The most striking feature of this study was the effect of the addition of low concentrations of meropenem on the development of levofloxacin-induced resistance. The meropenem concentration $(0.25 \times \mathrm{MIC})$ was chosen on the basis of results obtained with the checkerboard method. Cycling of the two pneumococcal strains in the presence of different concentrations of levofloxacin led to a stepwise increase in resistance until high-level resistance (MIC, $64 \mathrm{mg} / \mathrm{l}$ ) was reached after 12 cycles for both strains. This increase in resistance is based on point mutations in genes encoding for the two target enzymes, i.e. topoisomerase IV ( $\operatorname{arC} C$ ) and gyrase ( $g y r A)$. The mutations presented in Table 1 have already been described in pneumococci $[17,20,21,22]$. On the other hand, addition of meropenem to the same pneumococcal cultures almost completely impeded levofloxacin-induced resistance in WB4 during 12 cycles. In KR4, only a twofold increase in the MIC occurred after nine cycles, correlating with the single mutation detected in parE (Asp435 $\rightarrow$ Asn). One might speculate about the underlying mechanism of this effect, but basically two scenarios are conceivable. First, on the basis of the synergy observed between these two antibiotics, the bacterial population might be lowered for a longer period below the critical level that allows selection of mutations (i.e. below $10^{6}-10^{8} \mathrm{cfu} / \mathrm{ml}$ ). Second, the prevention of mutations might be due to the combined antibacterial effect of antibiotics with different targets ( $\beta$-lactam agents and quinolones). This hypothesis seems less likely because the MIC of levofloxacin was not influenced by the addition of meropenem in low concentrations, although slight interaction on the cellular level might be missed by the determination of MICs.

In experimental meningitis, antibiotic doses were chosen in order to mimic levels achieved in humans. Two injections of $125 \mathrm{mg} / \mathrm{kg}$ of meropenem led to CSF levels in rabbits ranging between 5.4 and $1.25 \mathrm{mg} / \mathrm{l}$, which correspond closely to levels obtained in humans with bacterial meningitis $(6.47-0.90 \mathrm{mg} / \mathrm{l}$ [23]). One injection of levofloxacin in rabbits $(10 \mathrm{mg} / \mathrm{kg})$ led to slightly higher peak levels than those measured in humans 
after $500 \mathrm{mg}$ b.i.d. (peak levels: $3.4 \mathrm{mg} / \mathrm{l}$ in rabbits vs. $2.56-1.29 \mathrm{mg} / \mathrm{l}$ in humans) [24].

One of the most interesting feature of this study was the efficacy of the combination regimen compared with the monotherapies $(-0.93$ for the combination regimen vs. -0.45 and $-0.44 \Delta \log _{10} \mathrm{cfu} / \mathrm{ml} \cdot \mathrm{h}$ for meropenem and levofloxacin monotherapy, respectively). The antibacterial efficacy of meropenem monotherapy was comparable to that reported in a previously published study with the same experimental setting [8], and levofloxacin was slightly more efficacious, with similar peak levels in CSF [25]. It is noteworthy that the actual combination regimen (meropenem + levofloxacin) against the same strain WB4 was more efficacious than the standard regimen based on ceftriaxone and vancomycin (ca. -0.50 for the standard regimen vs. $-0.9 \Delta \log _{10} \mathrm{cfu} / \mathrm{ml}$ h for meropenem combined with levofloxacin, respectively $[13,26])$.

Synergy between quinolones and cell-wall-active antibiotics, i.e. vancomycin, in experimental meningitis is not new $[13,26]$. In cycling experiments in vitro, we have previously shown that vancomycin reduced ciprofloxacinand trovafloxacin-induced resistance in the same strain (WB4), but at a lower order of magnitude [19].

The combination regimen based on meropenem and levofloxacin was very efficacious in experimental meningitis, sterilizing the CSF of rabbits within $6 \mathrm{~h}$. This regimen drastically reduced the risk of development of quinolone resistance in vitro. In summary, we have demonstrated that a combination of a broad-spectrum carbapenem, i.e. meropenem, and a quinolone, i.e. levofloxacin, fulfills all prerequisites of an ideal therapeutical regimen needed in the empiric treatment of bacterial meningitis.

Acknowledgement This study was supported by a grant of AstraZeneca AG, Switzerland.

\section{References}

1. Jacobs MR (1999) Emergence of antibiotic resistance in upper and lower respiratory tract infections. Am J Manag Care 5 [Suppl]:651-661

2. Davies TA, Evangelista A, Pfleger S, Bush K, Sahm DF, Goldschmidt R (2002) Prevalence of single mutations in topoisomerase type II genes among levofloxacin-susceptible clinical strains of Streptococcus pneumoniae isolated in the United States in 1992 to 1996 and 1999 to 2000. Antimicrob Agents Chemother 46:119-124

3. Chen DK, McGeer A, Azavedo JC de, Low DE (1999) Decreased susceptibility of Streptococcus pneumoniae to fluoroquinolones in Canada. N Engl J Med 341:233-239

4. Schmitz FJ, Fisher A, Boos M, Mayer S, Milatovic D, Fluit AC (2001) Quinolone-resistance mechanisms and in vitro susceptibility patterns among European isolates of Streptococcus mitis, Streptococcus sanguis, and Streptococcus pneumoniae. Eur J Clin Microbiol Infect Dis 20:219-222

5. Davidson R, Cavalcanti R, Brunton JL, Bast DJ, Azavedo JC de, Kibsey P, Fleming C, Low DE (2002) Resistance to levofloxacin and failure of treatment of pneumococcal pneumonia. N Engl J Med 346:747-750
6. Kaplan SL, Mason EO Jr (1998) Management of infections due to antibiotic-resistant Streptococcus pneumoniae. Clin Microbiol Rev 11:628-644

7. McCullers JA, English BK, Novak R (2000) Isolation and characterization of vancomycin-tolerant Streptococcus pneumoniae from the cerebrospinal fluid of a patient who developed recrudescent meningitis. J Infect Dis 181:369-373

8. Gerber CM, Cottagnoud M, Neftel KA, Tauber MG, Cottagnoud P (1999) Meropenem alone and in combination with vancomycin in experimental meningitis caused by a penicillinresistant pneumococcal strain. Eur J Clin Microbiol Infect Dis 18:866-870

9. Dacey RG, Sande MA (1974) Effect of probenecid on cerebrospinal fluid concentrations of penicillin and cephalosporin derivatives. Antimicrob Agents Chemother 6:437-441

10. Nau R, Kaye K, Sachdeva M, Sande ER, Tauber MG (1994) Rifampin for therapy of experimental pneumococcal meningitis in rabbits. Antimicrob Agents Chemother 38:1186-1189

11. Simon HJ, Yin EJ (1970) Microbioassay of antimicrobial agents. Appl Microbiol 19:573-579

12. Lack S, Hotchkiss RD (1960) A study of genetic material determining an enzyme activity in pneumococcus. Biochem Biophys Acta 39:508-518

13. Cottagnoud P, Acosta F, Cottagnoud M, Neftel K, Tauber MG (2000) Synergy between trovafloxacin and ceftriaxone against penicillin-resistant pneumococci in the rabbit meningitis model and in vitro. Antimicrob Agents Chemother 44:2179-2181

14. Eliopoulos GM, Moellering RC (1996) Antimicrobial combinations. In: Loarina V (ed.) Antibiotics in laboratory medicine, 4th edn. Williams \& Wilkins, Baltimore, pp 330-396

15. Entenza JM, Vouillamoz J, Glauser MP, Moreillon P (1997) Levofloxacin versus ciprofloxacin, flucloxacillin, or vancomycin for treatment of experimental endocarditis due to methicillin-susceptible or -resistant Staphylococcus aureus. Antimicrob Agents Chemother 41:1662-1667

16. Sambrook J, Fritsch F, Manaiatis T (1989) Molecular cloning: a laboratory manual, 2nd edn. Cold Spring Harbor Laboratory Press, Cold Spring Harbor, NY

17. Pan XS, Fisher LM (1996) Cloning and characterization of the parC and parE genes of Streptococcus pneumoniae encoding DNA topoisomerase IV: role in fluoroquinolone resistance. J Bacteriol 178:4060-4069

18. Gerber CM, Cottagnoud M, Neftel K, Tauber MG, Cottagnoud P (2000) Evaluation of cefepime alone and in combination with vancomycin against penicillin-resistant pneumococci in the rabbit meningitis model and in vitro. J Antimicrob Chemother 45:63-68

19. Cottagnoud P, Entenza JM, Cottagnoud M, Que YA, Moreillon P, Tauber MG (2001) Subinhibitory concentrations of vancomycin prevent quinolone-resistance in a penicillin-resistant isolate of Streptococcus pneumoniae. BMC Microbiol 1:9

20. Gootz TD, Zaniewski R, Haskell S, Schmieder B, Tankovic J, Girard D, Courvalin P, Polzer RJ (1996) Activity of the new fluoroquinolone trovafloxacin $(\mathrm{CP}-99,219)$ against DNA gyrase and topoisomerase IV mutants of Streptococcus pneumoniae selected in vitro. Antimicrob Agents Chemother 40:26912697

21. Munoz R, De La Campa AG (1996) ParC subunit of DNA topoisomerase IV of Streptococcus pneumoniae is a primary target of fluoroquinolones and cooperates with DNA gyrase A subunit in forming resistance phenotype. Antimicrob Agents Chemother 40:2252-2257

22. Tankovic J, Perichon B, Duval J, Courvalin P (1996) Contribution of mutations in gyrA and parC genes to fluoroquinolone resistance of mutants of Streptococcus pneumoniae obtained in vivo and in vitro. Antimicrob Agents Chemother 40:2505-2510

23. Dagan R, Velghe L, Rodda JL, Klugman KP (1994) Penetration of meropenem into the cerebrospinal fluid of patients with inflamed meninges. J Antimicrob Chemother 34:175-179

24. Scotton PG, Pea F, Giobbia M, Baraldo M, Vaglia A, Furlanut M (2001) Cerebrospinal fluid penetration of levofloxacin in 
patients with spontaneous acute bacterial meningitis. Clin Infect Dis 33:109-111

25. Nau R, Schmidt T, Kaye K, Froula JL, Tauber MG (1995) Quinolone antibiotics in therapy of experimental pneumococcal meningitis in rabbits. Antimicrob Agents Chemother 39:593597
26. Rodoni D, Hanni F, Gerber CM, Cottagnoud M, Neftel K, Tauber MG, Cottagnoud P (1999) Trovafloxacin in combination with vancomycin against penicillin-resistant pneumococci in the rabbit meningitis model. Antimicrob Agents Chemother 43:963-965 